\title{
Sputum induction in severe exacerbations of asthma: safety of a modified method
}

\section{To the Editors:}

Sputum induction with hypertonic saline is one of the most commonly used and reliable noninvasive methods to examine airway inflammation. The safety of induced sputum has been the subject of many reports focusing on stable asthma of any severity and the procedure is regarded as safe [1]. However, data on safety of induced sputum in acute asthma is limited. In a previous small study, we safely induced sputum in 10 patients with severe exacerbations of asthma using a modified method: starting the induction with isotonic saline, followed by the inhalation of hypertonic saline if necessary [2]. Here, we further examined the safety of this method in a larger number of patients.

The data were obtained from 45 patients (18-60 yrs of age; 29 patients were female, 32 were atopic and 21 were taking inhaled steroids) with asthma previously diagnosed by objective measurements and who were seen for the first visit of another clinical study of moderate-to-severe exacerbations of asthma. A severe exacerbation of asthma was defined as previously described [2]. All patients were either nonsmokers or exsmokers $(<10$ pack-yrs) for $>1 \mathrm{yr}$. None had other lung diseases. The Research Ethics Board of the Federal University of Santa Catarina (Santa Catarina, Brazil) approved the study and each patient gave written informed consent.

Subject characteristics were documented using a structured questionnaire. Asthma control was measured using the Asthma

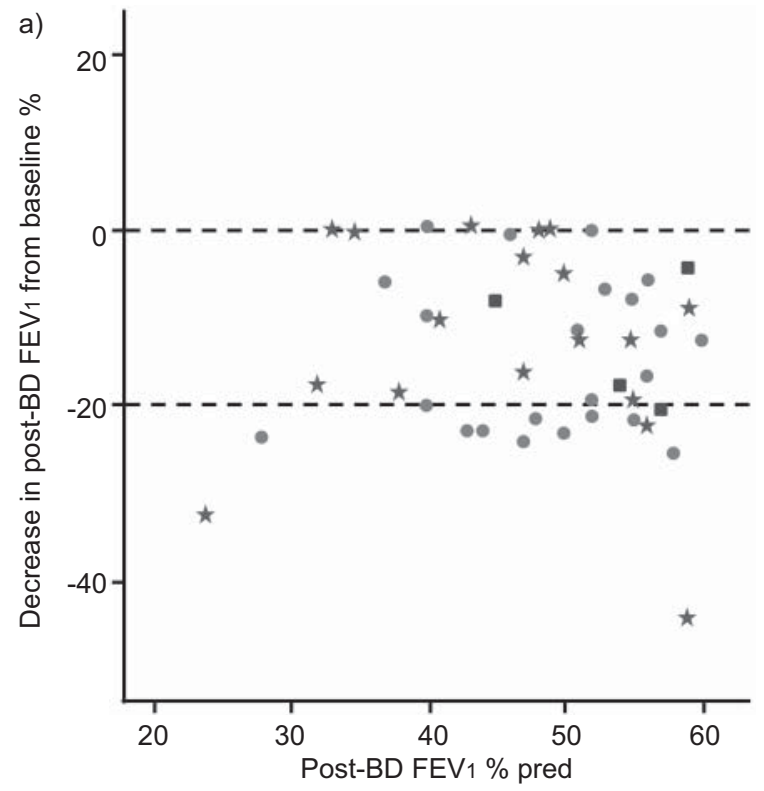

Control Questionnaire (ACQ) [3]. Spirometry was performed before and $20 \mathrm{~min}$ after administration of $400 \mu \mathrm{g}$ inhaled salbutamol via a pressurised metered-dose inhaler and aerochamber spacer [4]. Allergy skin prick tests were performed using a modified prick technique [5]. Sputum induction was performed after pre-treatment with $400 \mu \mathrm{g}$ salbutamol by inhalation, for repeated periods of 1-2 $\mathrm{min}$, of an aerosol of isotonic saline only or followed by hypertonic (3-4\%) saline [2]. The sputum was examined as described by PIZZICHINI et al. [6].

Sputum induction was successful in 42 (93\%) subjects. The mean duration of the procedure was $10 \mathrm{~min}$ (range 1-21 $\mathrm{min}$ ). The final saline concentration in each induction was $0.9 \%$ in 18 $(40.0 \%), 3.0 \%$ in $23(51.1 \%)$ and $4.0 \%$ in four $(8.9 \%)$ subjects. After sputum induction, there was a decrease in postbronchodilator forced expiratory volume in $1 \mathrm{~s}$ (FEV1) of $\geqslant 20 \%$ in $14(31.1 \%)$ subjects. The greatest decrease in FEV1 (44\%) occurred after 3 min of inhalation of isotonic saline. Patients with and without a $\geqslant 20 \%$ decrease in FEV1 did not differ in relation to post-bronchodilator FEV1, dose of salbutamol in the preceding day, ACQ score, duration of induction or saline concentration (table 1 and fig. 1). However, the majority of patients with a decrease in FEV $1 \geqslant 20 \%$ were induced with isotonic and hypertonic saline. The bronchoconstriction caused by sputum induction was rapidly reversed in all subjects by administration of additional salbutamol. No patient required hospital admission.

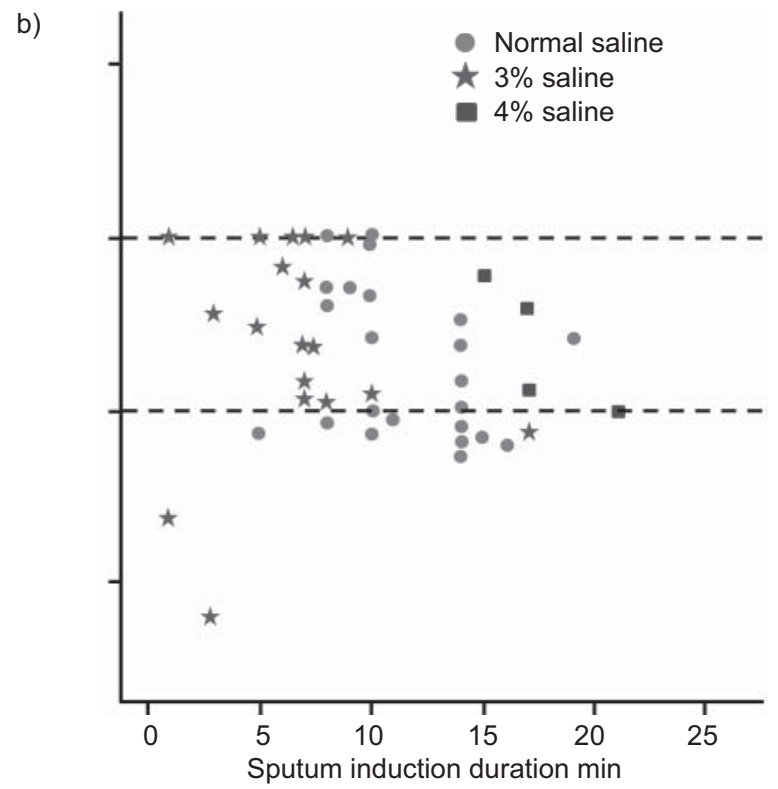

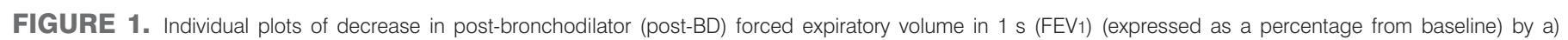

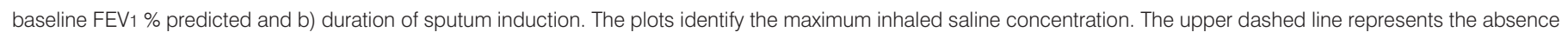

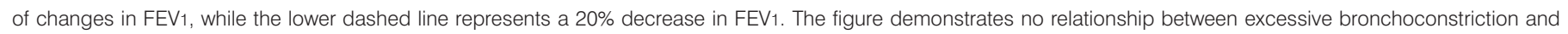
baseline $\mathrm{FEV}_{1} \%$ pred, saline concentration or duration of sputum induction. 


\begin{tabular}{|c|c|c|c|}
\hline \multirow{3}{*}{\multicolumn{2}{|c|}{$\begin{array}{l}\text { Characteristics o } \\
\text { excessive bronch } \\
\text { induction }\end{array}$}} & $\begin{array}{l}\text { patients with a } \\
\text { constriction a }\end{array}$ & $\begin{array}{l}\text { d without } \\
\text { ar sputum }\end{array}$ \\
\hline & & \multicolumn{2}{|c|}{ Decrease in FEV 1} \\
\hline & & $<20 \%$ & $\geqslant 20 \%$ \\
\hline \multicolumn{2}{|l|}{ Patients } & $31(68.9)$ & $14(31.1)$ \\
\hline \multicolumn{2}{|c|}{ Age yrs } & $36.2(32.0-40.0)$ & $36.6(29-43.6)$ \\
\hline \multicolumn{2}{|c|}{ Post-BD FEV 1 L } & $1.5(1.4-1.7)$ & $1.5(1.3-1.8)$ \\
\hline \multicolumn{2}{|c|}{ Post-BD FEV 1 \% pred } & $48.2(45.3-51.2)$ & $47.2(40.9-53.4)$ \\
\hline \multicolumn{2}{|c|}{$\Delta \mathrm{FEV}_{1}$ after $\mathrm{BD} \%$} & $26.5(19.5-33.5)$ & $21.3(4.9-37.6)$ \\
\hline \multicolumn{2}{|c|}{ Salbutamol rescue use puffs $\cdot$ day $^{-1}$} & $6.6(4.6-8.4)$ & $7.9(5.0-10.8)$ \\
\hline \multicolumn{2}{|c|}{ ACQ score } & $3.4(3.0-3.8)$ & $3.6(2.7-4.5)$ \\
\hline \multicolumn{2}{|c|}{ Duration of induction min } & $9.2(7.8-10.9)$ & $10.4(7.4-13.4)$ \\
\hline \multicolumn{4}{|c|}{ Maximum saline concentration } \\
\hline \multicolumn{2}{|c|}{ Isotonic saline } & 15 (83.3) & $3(16.7)$ \\
\hline \multicolumn{2}{|c|}{ Isotonic saline plus $3-4 \%$ saline } & $16(59.3)$ & $11(40.7)^{\#}$ \\
\hline
\end{tabular}

Data are presented as $\mathrm{n}(\%)$ or mean $(95 \% \mathrm{Cl})$. BD: bronchodilator (salbutamol); FEV1: forced expiratory volume in $1 \mathrm{~s}$; \% pred: \% predicted; $\Delta$ : change in; ACQ: Asthma Control Questionnaire. ${ }^{*}: p=0.08$

The results of this study confirm that sputum induction can be successful and safe in patients with a severe exacerbation of asthma if carefully performed. Excessive bronchoconstriction (a decrease in the post-bronchodilator FEV1 of $\geqslant 20 \%$ ) occurred in about a third of inductions, more often in patients induced with both isotonic and hypertonic saline, and it was rapidly reversed by a short-acting bronchodilator. No clinical parameter was a good predictor of excessive bronchoconstriction. The greatest decrease in the present study occurred after $3 \mathrm{~min}$ of induction with isotonic saline in a patient with a postbronchodilator FEV1 of 59\% pred. Hence, in severe exacerbations of asthma, sputum induction should be performed cautiously, with measurements of FEV1 at intervals of 1 or $2 \mathrm{~min}$. This is critical to maintain the safety of the procedure.

This is the first large study on the safety of induced sputum in severe exacerbations of asthma using both isotonic and hypertonic saline. Only one study has previously investigated the safety of sputum induction with isotonic saline in a large number of patients with acute asthma [7]. WARK et al. [7] examined 47 adults with moderate-to-severe acute asthma and demonstrated that their method could be performed safely in these patients. Despite differences in the method of induction, the reported proportion of patients with excessive bronchoconstriction (28\%) was similar to our results (31.1\%). However, in our study, excessive bronchoconstriction after induction occurred mostly in patients induced with hypertonic saline, and this was not related to duration of the procedure or to post-bronchodilator FEV1. Hence, in severe exacerbations of asthma, sputum induction must always start with isotonic saline.

Excessive bronchoconstriction may occur even in stable asthmatics, and the factors that might cause excessive bronchoconstriction during sputum induction in these patients are lower post-bronchodilator FEV1 [8], recent use of short-acting agonists $[8,9]$ and increased hyperresponsiveness to histamine [9]. WARK et al. [7] reported that in acute asthma, older age, use of ingested corticosteroids and excessive use of rescue salbutamol were predictors of significant bronchoconstriction. In the present study, we did not find any predictor of excessive bronchoconstriction. This discrepancy with previous publications may be due to subject selection and method of sputum induction.

In summary, we have demonstrated that sputum induction, if carefully performed by our method, can be successful and safe in severe exacerbations of asthma. However, there is a risk of significant bronchoconstriction that should not be underestimated.

\section{M.O. Vieira, E. Pizzichini, L.J. Marques Steidle, J. Kadletz da Silva and M.M.M. Pizzichini \\ NUPAIVA Research Center, Federal University of Santa Catarina, Santa Catarina, Brazil.}

Correspondence: M.M.M. Pizzichini, Division of Internal Medicine, Universidade Federal de Santa Catarina, NUPAIVA Hospital Universitário, Campus Universitário - Trindade, 88040970 Florianópolis, Santa Catarina, Brazil. E-mail: mpizzich@ matrix.com.br

Statement of Interest: None declared.

\section{REFERENCES}

1 Pizzichini E, Pizichini MMM, Leigh R, et al. Safety of sputum induction. Eur Respir J 2002; 20: Suppl. 37, 9s-18s.

2 Pizzichini MMM, Pizzichini E, Clelland L, et al. Sputum in severe exacerbations of asthma: kinetics of inflammatory indices after prednisone treatment. Am J Respir Crit Care Med 1997; 155: 1501-1508.

3 Juniper EF, O'Byrne, Guyatt GH, et al. Development and validation of a questionnaire to measure asthma control. Eur Respir J 1999; 14: 902-907.

4 American Thoracic Society. Standardization of spirometry. 1994 Update. Am Rev Respir Dis 1995; 152: 1107-1136.

5 Pepys J. Skin test in diagnosis. In: Gell PGH, Coombs RRA, Lachmann PJ, eds. Clinical aspects of immunology. 3rd Edn. Oxford, Blackwell Scientific Publications, 1976; pp. 55-80.

6 Pizzichini E, Pizzichini MMM, Ethimiadis A, et al. Indices of airway inflammation in induced sputum: reproducibility and validity of cell and fluid-phase measurements. Am J Respir Crit Care Med 1996; 154: 308-317.

7 Wark PAB, Simpson JL, Hensley MJ, et al. Safety of sputum induction with isotonic saline in adults with acute severe asthma. Clinical Exp Allergy 2001; 31: 1745-1753.

8 Pizzichini E, Pizzichini MMM, Burigo AC, et al. Sputum induction in stable steroid naive asthmatics: influence of prior use of $\beta_{2}$ agonist. Eur Respir J 1998; 12: Suppl. 28, 365s.

9 Ten Brinke A, de Lange C, Zwinderman AH, et al. Sputum induction in severe asthma by a standardized protocol-predictors of excessive bronchoconstriction. Am J Respir Crit Care Med 2001; 164: 749-753. 